\title{
Effects of Resource Materials on Implementation of Life Skills Education Programme in Manzini Region High Schools of Eswatini
}

\author{
Nonduduzo Mohale Racheal Mafumbate* \\ University of Eswatini, Department of Educational Foundations and Management, Faculty of Education
}

\begin{abstract}
The purpose of the study was to investigate the effects of resource materials on implementation of Life Skills Education programme in high schools in the Manzini region of Eswatini. The study was undertaken in four high schools in the Manzini region. This study was guided by Micheal Fullan's Educational Change Model. The purposively sampled participants consisted of head teachers and teachers. A qualitative approach and a case study design were used for the study. The head teachers were interviewed using a semi-structured interview schedule. Teachers were engaged in focus group discussions. Observations were done for all participants. Data was analysed using a thematic analysis approach. The findings revealed a myriad of factors that negatively affected the implementation of life skills. The factors included lack of adequate preparation of teachers and inadequate teaching/learning resource materials. The study also recommended that curriculum designers and Government should design and provide adequate support materials to teachers.
\end{abstract}

Keywords: implementation, Life Skills Education, resource materials.

DOI: $10.7176 / \mathrm{JEP} / 10-27-07$

Publication date:September $30^{\text {th }} 2019$

\section{Orientation}

Life skills originated from the 1986 Ottawa Charter of health that stated, under their rubric of personal and social development, the advantages for health and enhancing of life skills (Global Evaluation, 2012). Furthermore the need to focus on life skills as a critical response to the challenges facing young children today has found expression in international declarations such as the Convention of the Right of a Child (CRC, 1989), Education for All (EFA, 1990) and the United Nations General Assembly Special Session ( UNGASS, 2001).

According to the World Health Organization as reflected by Chaudhary and Mehta (2012), Life Skills refers to abilities for adoptive and positive behaviour that enables an individual to deal effectively with the demands and challenges of everyday. According to UNICEF (2012) "Life Skills" based education is important over numerical and literacy skills. Life skills area is not only linked to the pedagogy of active learning but also concerned with addressing the balance between knowledge, attitude and skills (Central Board of Secondary Education, 2013).

Furthermore, the World Health Organization (2013) categorizes life skills into the following three components: 1) critical thinking skills/decision-making skills including the skills of problem solving, decision making, critical thinking and creative thinking; 2) interpersonal/communication skills, consisting of effective communication, interpersonal skills and empathy; 3) coping and self-management skills like coping with emotions, coping with stress and self-awareness. Life skills are identified as a link between motivating factors of knowledge, attitude, values and behaviour reinforcement leading to positive behaviour; thus helping in primary prevention of health problems (Chaudhary \& Mehta, 2012).

According to UNICEF (2006) there are many challenges facing the youth all over the world as a result of globalization. These challenges are usually psychological, social as well as economical. These challenges are a result of numerous factors such as multifaceted developmental changes at puberty, lack of positive influence, negative mass media influence and social programming in compliance with stereotypes in society as well as inadequate source of information. It is further stated that life skills comprise of competencies that can enable the youth to handle life challenges and manage their lives from a positive perspective.

The introduction of FPE coincided with the introduction of the SADC child-friendly schools (SCF), which in Eswatini was adapted to suit local needs using the seven pillars (UNICEF, 1990; SADC, 2015; The MultiCountry Child Friendly Schools Capacity Development Workshop 11 Report, 2006).The local vision, according to an adaptation of SADC child friendly schools, was referred. to as "schools as centres of care and support" (SCCS) or Inqaba meaning "fortress". Schools are therefore expected to implement the Inqaba manual in their everyday operation, life skills is the $6^{\text {th }}$ pillar. This is supported by the Ministry of Education and Training MoET's Education Sector Policy (2011) in the SCCS framework section. As a member state, Eswatini through the leadership of MoET was and is bound to international and regional frameworks. It is against this background that Eswatini introduced Life Skills Education in 2015.

Life Skills Education was introduced in Eswatini high schools through government policy as a subject to be 
taught in high schools. Nonetheless, it is not known whether adequate training of teachers was done, relevant resource materials were provided and whether school stakeholders have embraced and supported the teaching of the new subject.

Being a new subject in the curriculum, life skills present certain requirement that have to be met for successful implementation. Mugambi and Rose (2013) state that the success in the implementation of new curriculum is characterized by: planning to adopt change to the local setting, teacher training that is concrete, specific and ongoing, necessary administrative and organizational arrangements for innovation, classroom consultation from and advice from resource personnel, modeling by more experienced teachers, active support of the principal and providing a conducive learning atmosphere.

Adeogun (2009) notes that it is the responsibility of the school administration and the state government to ensure that adequate resource materials are made available to the concerned schools. This will enable the schools to equip their students effectively and produce good performance on the part of both teachers and students; there is need for the provision of adequate human and materials resources in schools. Further according to Adeogun (2009) adequately of the human resources means having the right quantity and quality of staff in an organization.

However since LSE was introduced, serious problems have been hindering its full implementation. It is also at this root of this background that the researcher decided to undertake this study. This is particularly because of events that are unfolding with regard to the Implementation of the programme in Eswatini High Schools.

\section{Statement of the problem}

LSE aims at promoting behaviour change by developing attitudes, knowledge and skills which enable the individual to deal effectively with the demands and challenges of everyday life. This seems not to be the case in Eswatini schools. Risky behaviours are still witnessed in schools around Manzini. Dropouts due to unwanted pregnancies, early marriages, poor academic performance, drug and substance abuse, general indiscipline and riots are still on the increase. This suggests that the objective of LSE have not been achieved in the Manzini Region.

\section{The purpose of the study}

The purpose of the study was to investigate the effects of resource materials in the implementation process of Life Skills Education programme in Manzini High schools of Eswatini. The specific objective of the study was to find out how resource materials affect the implementation process of the Life Skills Education Programme in high schools in the Manzini Region, Eswatini.

\section{Review of related literature}

According to Lyons (2012) learning is a complex activity that involves interplay of student's motivation, physical facilities, teaching resources, and skills of teaching and curriculum demands. Availability of teaching/learning material therefore enhances the effectiveness of schools as they are the basic resources that bring about good academic performance in the students. The necessary resource that should be available for teaching and learning include material resource, human resource such as teachers and support staff and physical facilities such as laboratories, libraries and classrooms. Lyons (2012) further posits that these resources should be provided in quality and quantity in schools for effective teaching/learning process.

Owako (2010) refers resources not only to teaching methods and materials but also time available for instruction, the knowledge and skills of teachers acquired through training and experience. Githaiga (2011) established that most teachers were allocating LSE only one period a week. Some schools had no allocation at all in normal class hours, they only taught it after regular classes or any other time. The study also revealed that LSE time in the week was constantly eaten up by examinable subjects as teachers tried to cover the syllabus in order to generate good mean scores for their schools. In support of this, Root's (2002) study in South Africa indicated that in some cases LSE is not being taught at all despite the fact that it is included on the timetable. In some schools it was not even include on the time table. Therefore, the learners are inadequately prepared to deal with demands and challenges of every day's life.

Momoh (2010) revealed that the achievements of students in West Africa Schools Certificate Examination (WASCE) were related to the resources available for teaching. He concluded that material resources have a significant effect on students' achievement since they facilitate the learning of abstract concepts and ideas and discourage in rote learning. Ofodu (2012) noted that instructional facilities function as stimuli and support for both teacher and student during the teaching-learning process. Ofodu (2012) further argues that instructional resources are important catalysts for stimulating the students' interest, moving his perception towards the positive side and aid learners' attention span making learning more effective. They make it easy for students to acquire knowledge and skills which enable them to relate to the environment around them. The teacher should determine the best resource for a particular lesson and should be used in a most natural and logical manner to reinforce a particular activity. Nonetheless, instructional resources should simply complement teaching and 
learning and not replace the teacher (Abobo, Osero \& Orodho, 2014).

According to Abobo (2012), classroom teachers would be more successful in either English Language or Life Skills teaching if practical aids are used generously in the classroom activities so that learners are not made to become passive listeners in classroom. However, World Bank (2002) revealed that even when basic textbooks are available, schools in poor locations often lack other instructional facilities. A study in poor districts in India indicated that while majority schools in those districts had adequate textbooks and learning materials for learners, classrooms faced shortage of supplementary facilities in form of teacher guides and other instructional materials vital for effective teaching of life skills on HIV/AIDS in classrooms (World Bank, 2002).

Adhiambo (2013) observed that the quality and adequacy of such resources like physical, equipment, teaching and learning materials have a direct bearing on quality as they determine how effectively the curriculum is implemented. A wide variety of materials are necessary for effective teaching of any subject. These must be suitable, relevant, interesting and durable to benefit the learning process. Educational facilities and instructional materials are essential because they make teaching more effective and meaningful, increase the learner's motivation, concentration span and simplify skills being taught (Adhiambo (2013).

Abobo (2012) in her study found that most schools lack adequate teaching and learning materials including textbooks, reference materials, charts and videos causing poor implementation of educational programmes. Thus the level and availability of teaching and learning facilities affect the teaching of LSE in primary schools. Additionally physical facilities are vital for both teachers and pupils in the teaching and learning situations. Furthermore, Abobo (2012) indicated that instructional facilities are a major determinant to the success or failure in a teaching/learning situation. However, the availability of materials does not guarantee learning. Therefore these materials must be put in proper order, used or utilized at the right time with proper guidance to facilitate learning.

According to Kenya Institute of Curriculum Development (2012), resource materials are aids and other references that help a facilitator to prepare and present life skills activities effectively. Abobo, Osero \& Orodho (2014) established that instructional facilities are valuable possession used to enhance teaching and learning. They may be tangible or intangible facilities, human or non-human. In LSE tangible facilities include material equipment, media and books among others. Intangible resources include time, human skills, energy and knowledge. Additionally resource materials make the life skills activities real and interesting, enhance participants understanding of Life Skills activities and enable the participants to retain the knowledge, life skills and attitude learnt (Abobo, Osero \& Orodho 2014).

UNESCO (2011) established that the availability of a range of teaching and related equipment supplies, furniture and various forms of printed media for teachers and for learners is critical and facilitates the process of teaching and learning worldwide. Ngugi (2012) observed that the access to a range of resources and services enables teachers to capture the attention of the participant. There are some programmes on prevention of Skills Education (KICDE, 2012). Drugs and substance abuse, developed on radio and films, which may be used to implement Life Resource persons are knowledgeable people in various aspects such as drug and substance or in any other area of Life Skills Education (KICDE, 2012). The teacher's materials such as teacher's guide aim at helping the teacher to provide detailed instructions for teaching each particular section of a programme (KIE, 2012) In addition, it may contain background and enrichment materials as well as suggestions for supplementing activities.

Additionally Abobo, Osero and Orodho (2014) established that instructional facilities are valuable possessions used to enhance the teaching/learning process. They may be tangible or intangible, human or nonhuman. In Life Skills Education, tangible facilities include material equipment, media and books, among others. Intangible resources include time, human skills, energy and knowledge. Teaching/learning materials aid in enhancing learners' attention span making teaching/learning more effective. They make it easy for the students to acquire knowledge and skills enabling them to relate to the environment around them.

The teacher should determine the best resources for a particular lesson and the resource should be used in the most natural and logical manner known to reinforce a particular learning activity. However, the resources should complement teaching and learning and not replace the teacher. Some resources can be purchased or improvised from the environment, locally made, borrowed or shared at departmental inter-school levels (Ofodu, 2012). On another note Aila (2005) observed that teaching aids are important because they a used to increase learning, generate interest and create a situation where the student could fully engage in classroom activities.

Kadzamira (2006) revealed that the working environment in majority of schools in developing countries is deplorable with dilapidated school structures and large classes. These daunting conditions contribute to discontentment with their work. The low morale of teachers may affect their performance and consequently affect the implementation of any curriculum subject including Life Skills Education. This is supported by Oluwaglohumi (2008) who observed that electronic gadgets are never used due to irregular electricity that makes them operational in classrooms. These results implied absence of diverse instructional facilities in learning institutions negatively impact delivery of English language including life skills on HIV/AIDS. Prinsloo (2007) 
noted that overcrowding in classrooms acts as a barrier in the process of teaching curriculum subjects. Prinsloo quoted one teacher involved in his study on the implementation of life orientation as arguing that to reach 40 or more learners at the same time in a short period is difficult task. This comment reveals a perception that teachers feel that they are not always able to create an atmosphere of personal trust between themselves and all the learners in their class. This is supported by Lowe (2008) who explains that classes over 60 reduce the ability of teachers to teach.

Chirwa (2009) further found out that the implementation of life skills is constrained by a variety of social and structural contextual factors. Some of the crucial factors hampering the teaching and learning of life skills are poor conditions under which teachers are working. Teachers are paid very little salaries and this affects their motivation to teaching making some of these teachers giving most attention to what they perceive as priority subjects only such as Maths and Languages at the expense of Life Skills.

Okobia (2011) in his study on availability and use of instructional materials in the implementation of social studies curriculum in Junior Secondary Schools in Edo State of Nigeria discovered that most instructional resources were not available. Mutegi (2012) also found out that scarcity of teaching and learning materials for LSE has negatively impacted on its implementation. He further argued that no meaningful teaching and learning takes place without adequate resource materials. Children mainly learn through their interaction with materials readily available in their social and physical environment.

Additionally Abobo (2012) established that most schools lacked adequate teaching and learning materials including textbooks, teachers' guides, reference materials, charts and videos which caused negative implementation of LSE curriculum. The level of availability and adequacy of teaching and learning facilities affect the teaching of LSE in schools. Materials and physical facilities are vital for both teachers and pupils in the teaching and learning situation. He further argued that even if people were ready, willing and able to implement new policies, they cannot do so unless financial and material criteria were met. Any trace of inadequacy may lead to frustration and the motivated factor in terms of comfort diminishes. Implementation is facilitated when administrative personnel accepted the role of chief engineers of the system and act accordingly.

Lassa (2008) asserted that the success of any human endeavour, secondary school inclusive, is closely related to be quality of personnel who the tasks. He added that the extent to which public succeeds will depend to a large extent, upon the quality of personnel engaged in that educational process and upon the effectiveness with which they discharge individual and group responsibilities. He also pointed out that among all ingredients needed in making secondary education succeed, is the competency of personnel charged with the task of affecting desirable changes in children.

Muhammed (2011) carried out a study in Pakistan and he established that teachers with higher level of education teach well and are competent than those with low level of education. Academically qualified teachers had more authentic knowledge about the relevant subject than the academically less qualified teachers. Barbara (2004) concurred with Muhammed (2001), that quality teachers are the single greatest determinants of students achievement and further assert that teacher education, ability and experience account for variation in students achievements than all other factors. Therefore, it is vitally important that teachers be well prepared when they begin teaching and that they continue to improve their knowledge and skills throughout their career. Bakari (2009) suggests that students learn more from teachers with high academic skills than from teachers with low academic skills.

The effectiveness of any curriculum like life skills education depends on the quality of teachers that are there to translate the syllabus into practical instructional material in the class (Moseti, 2007). Osakwe (2014) indicated that a professionally trained teacher contributes more positively to effective learning than untrained teachers. Furthermore, Mutoro (2001) in his study found out that teacher training makes the teacher receptive and flexible in the implementation of any curriculum and also established that teachers experience adds value to the mastery of content which is major aspect of determining how teaching is manifested in the classroom.

The studies reviewed in this section seem to be suggesting that resources are critical in the implementation process of Life skills Education in schools. It is the observation of the researcher that there is scarcity of literature regarding the availability of resources to facilitate the implementation of Life Skills Education in high schools of Eswatini. There exists a gap there for the study to investigate the area of resources availability so that effects of resources on implementation can be greatly understood.

\section{Research methodology}

To satisfy the objectives of the study a qualitative approach was mainly employed to obtain in-depth rich information about the resource materials and implementation of Life Skills Education. The study was carried out as multiple case studies of four public high schools in the Manzini region. The study employed purposive sampling method in selecting information rich participants. The sample for this study was a total of 20 comprising of 4 head teachers and 16 Life Skills Education teachers. This study used different data collection instruments. This included interviews, focus group discussions, semi structured interviews and observation. 


\section{Findings}

The following is a summary of the major findings:

Inadequate resource materials for Life Skills Education: Data collected from the semi-structured interviews from the four (4) head teachers and all participants were of the view that schools lacked adequate resources to effectively implement the life skills education programme. Additionally, the majority of the teachers who participated were in agreement with the head teachers regarding the acute inadequacy of resource materials. This therefore became the first theme of the study and the key sub-themes that were reflected in the arguments of the participants included lack of conducive environment and inadequate teaching and learning materials. It was the submissions of the majority of both the head teachers and teachers who participated that teaching and learning materials for LSE was in short supply at their schools. These made it difficult to effectively and efficiently implement the programme.

Lack of conducive environment: It was the submission of 3 of the 4 head teachers who participated in the study that the classes were overcrowded. This made it difficult for the schools to secure the necessary books and materials for every single student in the school attending LSE. In the end, learners were compelled to share the available resources. The points raised by the participants as presented in this section regarding the environment were consistent with observation made by the researcher during the visits made to the four schools. In this regard, it was observed that in schools A and B most of the furniture was make shift in nature and the desks in use were the old twin ones. It was only in School C, where single desks with single chairs were used. Additionally, there was no ceiling and the classrooms walls were dirty and requiring repainting. The overall view of the conditions in schools A, B and D was that the classrooms were in a pitiful condition and required upgrading to make them inviting learning environments.

Additionally, it was observed that at school D, the classroom was so overcrowded that the teacher had little freedom to move around and check all 45 learners' work. In order to fit the huge number of students the desks had to be rearranged closing the gaps normally left for free movement. On this particular day, the temperatures were high and both teacher and students could be seen sweating profusely despite the opened windows and door. There was no additional air conditioning system. This visibly made the process of teaching learning very uncomfortable for both teacher and learners. It was however, observed that at school $\mathrm{C}$, the classroom used was quite spacious and single desks and chairs were available. The classroom was even equipped with a notice board although at the time of the observation session no notice was pinned.

Poor teaching strategies used by teachers: A second dominant theme referred to the majority of the participants was that of the teaching and learning strategies of LSE in schools. The most prominent issues drawn from the theme were poor instructional methods as well as the lack of competence among the teaching staff. It was the submissions on the majority of the participants that teachers used poor instructional strategies due to general lack of competence. It was the view of 3 out of the four head teachers who participated in individual interviews that teachers lacked competence in their instructional strategies due to short duration of training.

One of the key issues that were brought forward which closely relate to the quality of teaching and learning of LSE in schools was that of building capacity in the responsible teachers in order for them to be effective in their teaching. This appeared not to have been properly done upon the introduction of the programme. The participants further lamented lack of teacher capacity as reflected in the interviews held with the head teachers where the participants indicated that the majority of the teachers teaching the LSE programme did not have the appropriate qualifications. One head teacher was very strong in her mentioning of this point as she indicated that this had serious adverse impact on the quality of the LSE programme.

Lack of time to teach Life Skills Education: The teachers who took part in the focus group discussions pointed out that the time allocated for the LSE programme was not enough to cover what is required in such a practical subject. The point raised by these teachers was echoed by observation made by the researcher during visits made to the schools. In school D a lot of time was wasted when learners were taking out desks to open up space. In school D lesson consisted a debate on the topic: Should Learners use Cell Phones? Learners were to be given enough time working in groups getting themselves ready for the presentation but unfortunately the one hour was not enough and lesson was to be continued some other time.

\section{Discussion of findings}

Findings related to resource materials disclosed that teachers are working under poor conditions. Schools lack teaching and learning material, furniture and classrooms are overcrowded and buildings are dilapidated. With regards to the lack of conducive environment for LSE it was discovered through observations that the majority of the school's classrooms were in a pitiful condition and uninviting as a learning environment. This finding adheres to the findings by Kadzimira (2006) who noted that the working environment in the majority of schools in developing countries is deplorable with dilapidated school structures and large classrooms. These daunting conditions contribute to teacher discontentment with work. The low morale of teachers may affect their performance and consequently affects the implementation of LSE. 
It was the submission of the head teachers and the majority of the teachers who participated in the study that the classes were overcrowded. This made it difficult for the schools to secure the necessary books and materials for every single student in the school attending LSE. The problem of overcrowding in the classes of LSE was also confirmed by the researcher during observation sessions with some classes having close to $50+$ learners in a class. These findings can be linked to the finding made by Prinsloo (2007) who noted that overcrowding in classrooms acts as a barrier in the process of teaching Life Skills Education. This therefore reveals a perception that teachers feel that they are not always able to create an atmosphere of personal trust between themselves and all the learners. Prinsloo quoted one teacher involved in his study on the implementation of Life Orientation as arguing that to reach 40 or more learners at the same time in a short period is a difficult task.

Furthermore, regarding to inadequate teaching and learning materials it was the submissions of the majority of both the head teacher and teachers who participated in this study that teaching and learning materials for LSE were in short supply at their schools. The results of the findings agree with Abobo (2015) who established that most schools lacked adequate teaching and learning materials including textbooks, teachers' guide reference materials, charts and videos which caused negative implementation of LSE curriculum. The level of availability and adequacy of teaching and learning facilities affects the teaching of LSE in schools. Materials and physical facilities are vital for both teachers and pupils in the teaching and learning situation. He concluded that even if people were ready, willing and able to implement new policies, they cannot do so unless financial and material criteria were met. Any trace of inadequacy may lead to frustration and the motivating factor in terms of comfort diminishes (Abobo, 2015).

Such findings are quite consistent with the findings made by Adhiambo (2013) who noted that adequacy of such resources: as physical, equipment, teaching and learning materials have a direct bearing on quality as they determine how effectively the curriculum is implemented. He further argued that these must be suitable, relevant, interesting and durable to benefit the learning process. Educational facilities and instructional materials are essential because they make teaching more effective and meaningful, increase the learner's motivation, concentration span and simplify skills being taught (Adhiambo (2013).

This conforms to Mutegi (2012) who cited scarcity of teaching and learning materials as negatively impacting on the implementation of LSE programme because children mainly learn through their interaction with materials readily available in their social and physical environment.

In terms of poor instructional methods used by teachers, the study revealed that teachers used poor instructional methods due to general lack of competence. Question and answer method were preferred by majority of teachers due to lack of resources and ability to involve pupils. This implies that teachers use methods that are convenient and do not require a lot of time and resources in implementing the programme. It was also said by the participants that they needed more formal training to gain competence in the teaching of the subject. Such findings are quite complemented by the findings of Wanjama, Muraya and Gichaga (2010) who posit that appropriate choice of teaching methods accompanied with relevant learning resources trigger the desired learning concepts in any other subject including Life Skills Education.

Additionally, Boyd (2011) revealed that teachers require a variety of methods to cater for individual differences of learners. He further stated that effective implementation of skill based curriculum requires the use of collaborative strategies which can make classroom life supportive, engaging, intellectually stimulating, creative, productive and fun for both the teacher and learners. It could be seen that if the teachers confirmed lack of competence in the teaching of LSE, this would reflect on the poor quality of delivery and ultimately defeats the purpose of the programme being implemented.

Furthermore findings revealed that teachers lacked the capacity to effectively run the programme and needed capacity building in order for them to be improving the quality and effectiveness of teaching. Teachers lamented that they were not prepared for the implementation of the Life Skills Education Programme in the majority of schools. The majority also voiced their concern regarding the need for training in order for them to be competent in their work. These findings are very much consistent with the findings of Gichaga (2010) who argued that when teachers are not trained for Life Skills, and do not have enough knowledge and confidence to teach students, the programme cannot be a success.

Additionally, Bakari (2010) suggests that students learn more from teachers with high academic skills than from teachers with low academic skills. The effectiveness of any curriculum like life skills education depend on the quality of the teachers that are there to translate the syllabus into practical instructional material in the class. This supports the fact that for the LSE programme to be effective the teachers need to be fully trained so that they are competent and confident with the work they are doing. Therefore, teachers' professional training is vitally important for improving student performance.

According to Fullan (2001) some teachers, depending on their previous experiences and stage of career, are more self-actualized and have a greater sense of efficacy, which leads them to take action and persist in the effort required to bring about successful implementation. It is important to note that most teachers in this study had adequate years of experience in teaching; they were unlikely to have necessary skills needed for successful 
implementation of life skills curriculum because most of them have not been oriented.

Regarding the lack of time for teaching LSE, multiple responses given by participants revealed that time allocated is not adequately enough to complete the syllabus. Hence this could affect the implementation of LSE. This finding concurs with that by Githaiga (2011) who established that most teachers were allocating LSE only one period a week. Some schools had no allocation at all in normal class hours, they only taught it after regular classes or any other time. The study also revealed that LSE time in the week was constantly eaten up by examinable subjects as teachers tried to cover the syllabus in order to generate good mean scores for their schools. In support of this, Root's (2002) study in South Africa indicated that in some cases LSE is not being taught at all despite the fact that it is included on the timetable. In some schools it was not even include on the time table. Therefore, the learners are inadequately prepared to deal with demands and challenges of every day's life.

\section{Conclusions}

From the findings of the study it can be concluded that teaching and learning materials for teaching Life Skills Education were inadequate in high schools. This implies that unavailability of teaching and learning materials is the major factor contributing negatively to effective implementation of LSE programme in high schools. No meaningful teaching and learning takes place without resource materials since children mainly learn through their interaction with materials readily available in the social and physical environment Therefore, the instructional materials at high schools are central to the implementation of LSE programme. Thus, teaching of LSE proved to be inadequate and problematic in majority of schools given the demanding nature of the subject necessitating a wide variety of materials for effective teaching which must be of relevance and interesting to positively impact the learning process.

\section{Recommendations}

The study made the following recommendations for action:

- the study recommends that curriculum developers should design and provide adequate support materials to enhance effective implementation of LSE since children learn more through interaction with learning materials; and

- MoET should upscale their effort of orientation of teachers through seminars and workshops on LSE curriculum to empower teachers on delivery approaches of LSE.

\section{References}

Abobo, F. (2015). Influence of instructional facilities on teaching of life skills on HIV/AIDS in secondary schools in Gucha South District, Kenya. Merit Research Journal of Education and review, 3 (5), 208-214.

Abobo, F., Osero, P. O. \& Orodho, J. A. (2014). Resource Management Strategies and Learners Academic Performance. 10SR Journal of Dental and Medical Science, 13(14), 14-23.

Adeogum, A. (2009). Instructional resources and school effectiveness in private and public Secondary Schools in Lagos State. Lagos Journal of Education Administration and Planning, 3 (1), 74-81.

Adhiambo, P. L. (2013). Implementation of Life Skills Education in Secondary Schools in Uriri and Awendo Districts, Migori County, Kenya.Unpublished Research Project MED of Kenyatta University.Homebay District.

Aila, H. I. (2003). Factors influencing the use of visual aids in pre-school in Asego division. Unpublished Manual Kenyatta University.

Bakari, G. S. (2009). Literacy for community based socio-economic transformation and development of Nigeria: Some critical challenges and the role of the international reading association. A paper presented at the $6^{\text {th }}$ Pan African reading for all conference, university of Dar Er Salam, Tanzania.

Barbara, L. (2004). Teachers' professional development: A primer for parents and community member. Good printers Inc.

Braun, V. \& Clarke, V. (2006).Using thematic analysis in psychology: qualitative research http://www.informaworld.com/tupp/content=979512719from-title.link.

Burns, N. \& Groove, S. (2007). Understanding nursing research: Building in evidence-based practice. St. Louis, MO: Elsevier.

Chaudhary, S \& Mehta, B. (2012). Life Skill Education for the economically backward adolescent boys and girls: An Intervention Programme, International Journal of Social Sciences \& Interdisciplinary Research, 1(5), 788-794.

Hancock, B. (2002). Research and development in health care. An Introduction to qualitative research. Trent Focus Group. University of Nottingham.

Githinji, E.W. (2011). Secondary school learners' perception and expectations of Life Skills Education: a case study of Kieni East division, Nyeri North District, Kenya. Paper presented at department of Curriculum 
Development Studies, Kenyatta University: Nairobi.

Global Evaluation of Life Skills Education Programs (2012). http:/www.UNICEF.org/evaluation/files/-skillseducation-management-response-to-evaluation.pdf. Retrieved 20/02/2018.

Kenya Institute of Curriculum Development (2012). Primary life skills education teacher's handbook. Nairobi: Kenya Institute of Education Kenya Institute of Curriculum Development.

Lassa, P.(2008). Teacher production a focus in Nigeria: The state of education in Nigeria. Journal of Education, 2(2), 11-19.

Muhammed, D. (2011). Impact of teacher quality on academic achievement of students at secondary stage in Punjab. Journal of International Cooperation in Education. Vol.12 No.1, 107-125.

Mutegi, L. (2012). School factors influencing the implementation of life skills education in public primary schools in Athi-River District, Kenya. Unpublished MED Thesis, University of Nairobi.

Moseti, P. (2007). Teaching/Learning strategies in intergrated English course and their effects on performance in Manga division Nyamira district, Unpublished MED thesis. Nairobi: Kenyatta University.

Ngugi, G. (2012). Teachers perception of relationship between Life Skills Education, sexual reproductive health and HIV prevention among secondary students. Nairobi Presentation at SAID; Washington D.C.

Ofodu, G. O. (2012). Instructional strategies and resource utility in language teaching among basic educators in 21st Century Nigeria. Published by Canadian Centre of Science and Education.

Okobia, E. O. (2011). Availability of teachers use of instructional materials and resources in the implementation of social studies in junior secondary in Edo State, Nigeria.

Osakwe, R. N. (2014). Classroom management: A tool for achieving quality Secondary School education in Nigeria. International Journal of Education, 6 (2), 58.

Prinsloo, M. (2009). Thinking locally, acting globally: The new illiteracies as placed resources. In Literacy, new technologies \& education: Aspects of the local and global, D. Koutsogiannis and M. Arapapoulou (eds.) Thessaloniki: Ziti publications.

UNESCO. (2014). EFA Global Monitoring Report 2013/4 - Teaching and Learning: Achieving Quality for All. Paris, UNESCO.

UNICEF (2012).Global Evaluation of Life Skills Education Programme. New York: UNICEF.

UNICEF (2006). Report on the National Life-Skills Education Forum. Nairobi: UNICEF.

UNGASS Declaration of Commitment (2001).Capacity building activities on life skills and peer education. New York: June 2001. www.aseansec.org/aids/10.pdf retrieved: 15/01/2018.

United Nations Children's Fund (2014).Progress for Children.Achieving the MDGS with Equity.UNICEF.

World Bank (2002). The Global Impact Scaling up HIV/AIDS Prevention Programs in Low and Middle Income Countries. 